\title{
A novel mutation of exon 7 in growth hormone receptor mRNA in a patient with growth hormone insensitivity syndrome and neurofibromatosis type I
}

\author{
JU-HYUNG KANG ${ }^{1}$, OK-SOON KIM ${ }^{2}$, JA-HYUN KIM ${ }^{2}$, SEONG-KYU LEE ${ }^{2}$, \\ YOUN-JONG PARK ${ }^{1}$ and HAING-WOON BAIK ${ }^{2}$ \\ Departments of ${ }^{1}$ Pediatrics, ${ }^{2}$ Biochemistry and Molecular Biology, School of Medicine, \\ Eulji University, Daejeon 301-832, Republic of Korea
}

Received March 21, 2012; Accepted May 28, 2012

DOI: $10.3892 / \mathrm{ijmm} .2012 .1048$

\begin{abstract}
Growth hormone insensitivity syndrome (GHIS), a genetic disease characterized by growth retardation combined with high serum concentration of growth hormone $(\mathrm{GH})$ and low insulin-like growth factor 1 (IGF-1) levels, can be caused by mutations in the $G H$ receptor (GHR) gene. We investigated the molecular defects in the GHR gene in a patient with neurofibromatosis type 1 (NF-1). The patient, a 2-year-old boy with NF-1, was assessed on his short stature by auxological, biochemical and molecular studies. Height of the patient and his family members were measured and compared to normal control. Serum concentrations of GH, IGF-1 and IGF-binding protein 3 (IGFBP3) in the patient were measured during a GH stimulation test. We examined the GHR gene in the patient and his parents. Genomic DNA and mRNA of the GHR gene were extracted from peripheral lymphocytes. All the exons and the flanking regions of the GHR gene were amplified by PCR, and directly sequenced. The patient's height was $75 \mathrm{~cm}$ (-2.89 SDS) with gradually reducing growth velocity, while the heights of the other family members were within the normal range. The GH stimulation test revealed that serum GH concentrations in the patient were much higher than those in the control group, and serum IGF-1 and IGFBP 3 levels were extremely low. There was no germline mutation in the exons or the flanking regions of the patient's $G H R$ gene. Interestingly, a deletion of 166 bases of exon 7 in the GHR mRNA was found, and it was suggested that the novel mutation resulted in premature termination (M207 fs. $\mathrm{X} 8$ ). This mutation decreases GH binding affinity to the GHR, and, thus, would be responsible for growth retardation.
\end{abstract}

Correspondence to: Professor Haing-Woon Baik, Department of Biochemistry and Molecular Biology, School of Medicine, Eulji University, Daejeon 301-832, Republic of Korea

E-mail: baikhw@eulji.ac.kr

Key words: growth hormone insensitivity syndrome, neurofibromatosis type I, GHR mRNA mutation

\section{Introduction}

Neurofibromatosis type 1 (NF-1) is a common genetic disorder that is transmitted by autosomal dominant inheritance, and is diagnosed when two of the following signs are found in individuals: six or more cafe-au-lait spots over $5 \mathrm{~mm}$ in greatest diameter during prepubertal period, freckling in the axillary or inguinal region 2-3 $\mathrm{mm}$ in diameter, two or more Lisch nodules in the iris, optic gliomas, two or more neurofibromas or one plexiform neurofibroma, skeletal abnormalities such as a distinctive osseous lesion like sphenoid dysplasia or pseudo-arthritis, or family history of a first degree relative with NF-1 (1).

Short stature, defined as a height that is less than 2 standard deviations to the population mean, has been known to be one of the most common complications in NF-1. Although it is known to be associated with several clinical risk factors related to NF-1, the exact mechanism for short stature is not yet defined (2).

Growth hormone insensitivity syndrome (GHIS) is known to be a very rare genetic disorder with an autosomal recessive inheritance, and is characterized by normal or elevated $\mathrm{GH}$ concentration, very low insulin-like growth factor 1 (IGF-1) and IGF-binding protein 3 (IGFBP3) levels in serum. GH binds to its receptor and then activates an intracellular signal transduction pathway, leading to the production of IGF-1. IGF-1 mediates the actions of GH and performs a negative feedback of GH secretion at the pituitary level. Any defect in this pathway results in GHIS. Consequently, patients with this syndrome have postnatal growth failure, leading to short adult stature, and abnormal facial morphologies such as frontal bossing of the forehead, hypoplasia of the midfacies and depressed nasal bridge $(3,4)$.

GHIS was first reported by Z. Laron in two siblings from an Oriental Jewish family, since then many cases have been described and most of them revealed gene defects of various proteins involved in the GH - IGF-1 signaling cascade $(5,6)$.

We examined a patient with GHIS accompanied by NF-1, the first reported case with biochemical and molecular analysis.

\section{Materials and methods}

Patient. A pediatric patient with growth retardation was brought to the department of pediatric endocrinology in our 
Table I. Oligonucleotide sequences of the GHR primer sets used in this study.

\begin{tabular}{|c|c|c|c|c|}
\hline & Sense primer $\left(5^{\prime} \rightarrow 3^{\prime}\right)$ & & Antisense primer $\left(5^{\prime} \rightarrow 3^{\prime}\right)$ & $\begin{array}{c}\text { Amplified } \\
\text { region }\end{array}$ \\
\hline Exon $2 \mathrm{~F}$ & GTCTGCTTTTAATTGCTGGGC & Exon $2 \mathrm{R}$ & ACACTGAGGGTGGAAATGGA & Exon 2 \\
\hline Exon $3 \mathrm{~F}$ & ССТСТTTCTGTTTCAGCCAC & Exon $3 \mathrm{R}$ & GGATAGTAGCTTAATTACACTA & Exon 3 \\
\hline Exon $4 \mathrm{~F}$ & AGGATCACATATGACTCACCT & Exon $4 \mathrm{R}$ & AGTGTACTTTAGTAGGTACATC & Exon 4 \\
\hline Exon $5 \mathrm{~F}$ & TAAGCTACAACATGATTTTTGG & Exon $5 \mathrm{R}$ & TTAGTCTAAAACTATGTCAAAG & Exon 5 \\
\hline Exon $6 \mathrm{~F}$ & GTGTCTGTCTGTGTACTAATG & Exon $6 \mathrm{R}$ & AGAAAAGTCAAAGTGTAAGGTG & Exon 6 \\
\hline Exon $7 \mathrm{~F}$ & TAGTGTTCATTGGCATTGAG & Exon $7 \mathrm{R}$ & ACAAAAGCCAGGTTAGCTAC & Exon 7 \\
\hline Exon $8 \mathrm{~F}$ & AAACTGTGCTTCAACTAGTCG & Exon $8 \mathrm{R}$ & GGTCTAACACAACTGGTACA & Exon 8 \\
\hline Exon $9 \mathrm{~F}$ & GAATATGTAGCTTTTAAGATGTC & Exon $9 \mathrm{R}$ & CATATGACAGGAGTCTTCAGGTG & Exon 9 \\
\hline Exon $10 \mathrm{~F}$ & GAGTTTCTTTTCATAGATCTTC & Exon $10 \mathrm{R}$ & GGTTTAAACATTGTTTTGGC & Exon 10 \\
\hline Exon $10-1 \mathrm{~F}$ & GATCTTCATTTTCTTTCTAT & Exon $10-1 \mathrm{R}$ & CTACCTGCTGGTGTAATGTC & Exon $10-1$ \\
\hline Exon $10-2 \mathrm{~F}$ & CATCGACTTTTATGCCCAGG & Exon $10-2 \mathrm{R}$ & ATGAATGGAGGTATAGTCTGG & Exon $10-2$ \\
\hline Exon 10-3 F & CATGTTCCAGGTTCTGAGAT & Exon 10-3 R & GGTTTAAACATTGTTTTGGC & Exon $10-3$ \\
\hline
\end{tabular}

hospital. The patient's birth, medical, nutritional and family history were reviewed. His height, weight and head circumference were measured and assessed by standard deviation score (SDS) as well as the assessment of growth velocity since birth. Informed consent was obtained from three family members who participated in the study.

Biochemical and imaging study. GH stimulation was performed. The basal serum concentrations of GH, IGF-1, IGFBP3, thyroid stimulating hormone (TSH) with free T4, luteinizing hormone $(\mathrm{LH})$, follicle stimulating hormone (FSH) and cortisol were measured. Serum concentrations of $\mathrm{GH}$ and cortisol were measured every $30 \mathrm{~min}$ during $120 \mathrm{~min}$ after stimulation of insulin (0.1 IU/kg, intravenously). Data of serum GH concentrations was also obtained from agematched control group $(n=10)$ and compared to those of the patient. This test was planned to be discontinued if hypoglycemic symptoms occurred or when serum glucose level after stimulation with insulin was $45 \mathrm{mg} / \mathrm{dl}$ or $<50 \%$ of basal level. Brain magnetic resonance imaging (MRI) scanning was also performed in order to investigate abnormal brain lesions associated with growth retardation.

Extraction of genomic DNA and total-RNA. Genomic DNA (gDNA) was isolated from the patient and his family members using Accuprep Genomic DNA extraction kit (Bioneer, Seoul, Korea), according to the manufacturer's instructions. Total-RNA extraction was carried out in two steps; leukocytes from whole blood were obtained in step I, RNA from the leukocytes was extracted in step II subsequently. Leukocytes were isolated from the patient, his family members and healthy control using Ficoll-Paque Plus (GE Healthcare, USA), according to the manufacturer's instructions.

Reverse-transcription polymerase chain reaction (RT-PCR). cDNA was synthesized from $4 \mu \mathrm{g}$ of total-RNA in a $20 \mu \mathrm{l}$ reaction mixture containing ImProm-II ${ }^{\mathrm{TM}}$ Reverse Transcription System (Promega, Madison, WI, USA). First strand cDNA was amplified using PCR. This mixture was placed at $42^{\circ} \mathrm{C}$ for $60 \mathrm{~min}$. The synthesized cDNA was incubated at $70^{\circ} \mathrm{C}$ for $10 \mathrm{~min}$, and then stored at $-80^{\circ} \mathrm{C}$. To verify the amplification, the PCR products were subsequently examined by $1.2 \%$ agarose gel electrophoresis.

Direct DNA sequencing. PCR amplification of all growth hormone receptor (GHR) exons, including the flanking intron regions, was performed on extracted DNA and RNA using previously described amplification primers and cycling conditions, as described by Vidal et al (7) with some modifications. Primer sequences used for amplification of human GHR gene fragments are listed in Table I.

The PCR amplifications were performed and the products were purified with a QIA-quick-PCR-purification kit (Qiagen, Germantown, MD, USA), and then directly sequenced with an ABI-3700 automated DNA sequencer (Applied-Biosystems, Foster City, CA, USA).

\section{Results}

Patient. The patient was a 2-year-old boy, who was born by normal vaginal spontaneous delivery with normal birth length and weight. No abnormal findings were observed on the neonatal screening test. The patient's mother and maternal grandfather were diagnosed with NF-1 (Fig. 1). Also, the patient was diagnosed with NF-1 at the age of 6 months when the patient had 6 or more cafe-au-lait spots with $>5 \mathrm{~mm}$ in greatest diameter on the body. The patient showed normal hair, frontal bossing and a depressed nasal bridge. On admission, $75 \mathrm{~cm}$ of height ( $<3$ percentile), $8.3 \mathrm{~kg}$ of weight ( $<3$ percentile), and $48 \mathrm{~cm}$ of head circumference (25-50 percentile) were recorded. Since birth, the patient had showed reduced growth velocity, resulting in postnatal growth failure (Fig. 2). The heights of the parents and maternal grandfather were within normal range.

Biochemical and imaging study. The GH stimulation showed that $\mathrm{GH}$ concentration was $4.13 \mathrm{ng} / \mathrm{ml}$ at $0 \mathrm{~min}$ but $94 \mathrm{ng} / \mathrm{ml}$ at $60 \mathrm{~min}$. The rapid increase in $\mathrm{GH}$ serum level following 


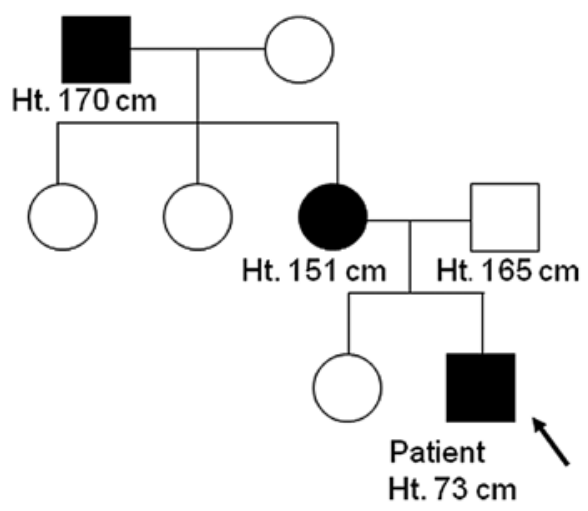

Figure 1. Pedigree of the family with neurofibromatosis type 1 (NF-1). Affected individuals indicated in solid symbols. The proband (arrow) shows a male who has a short stature.

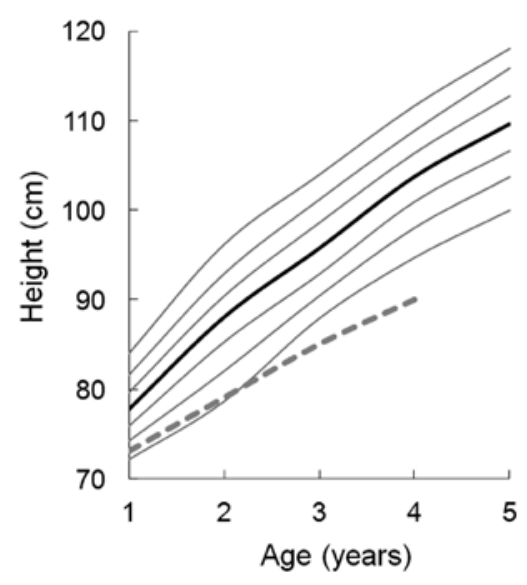

Figure 2. The growth chart of the patient is shown. Dotted lines represent the patient's growth pattern, which reveals a gradual decrease in growth velocity as the age increase.

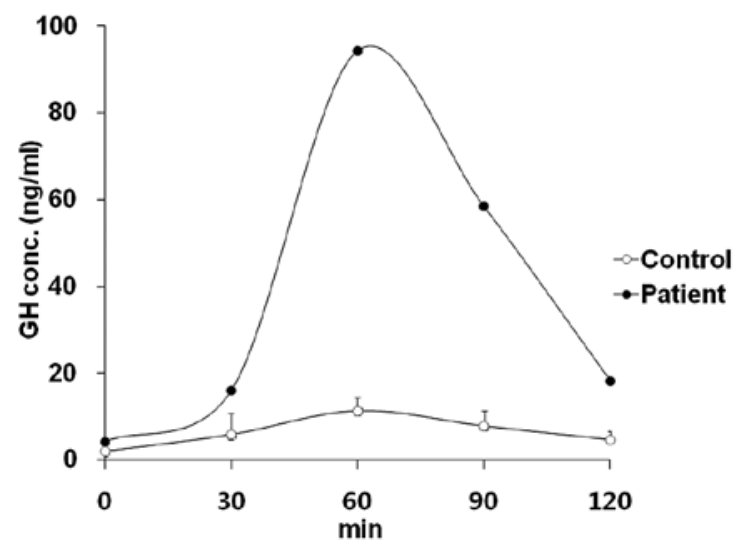

Figure 3. GH secretions in response to stimulation with insulin. Serum GH concentrations in the patient and the control group (mean $\pm \mathrm{SE}, \mathrm{n}=10)$ are shown.

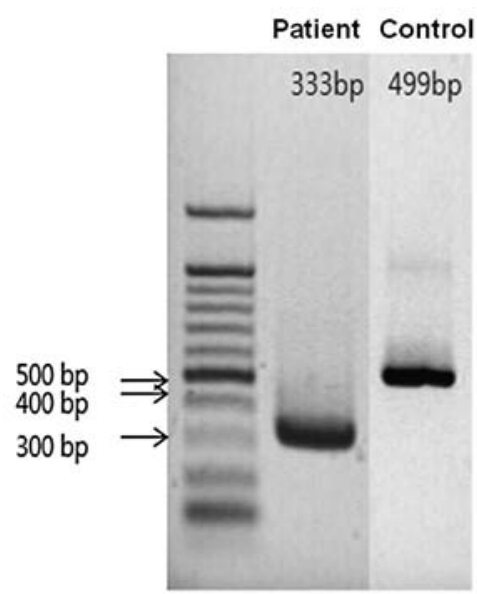

Figure 4. Agarose gel electrophoregram displaying a 166 bases deletion in exon 7 in the GHR mRNA in the patient.

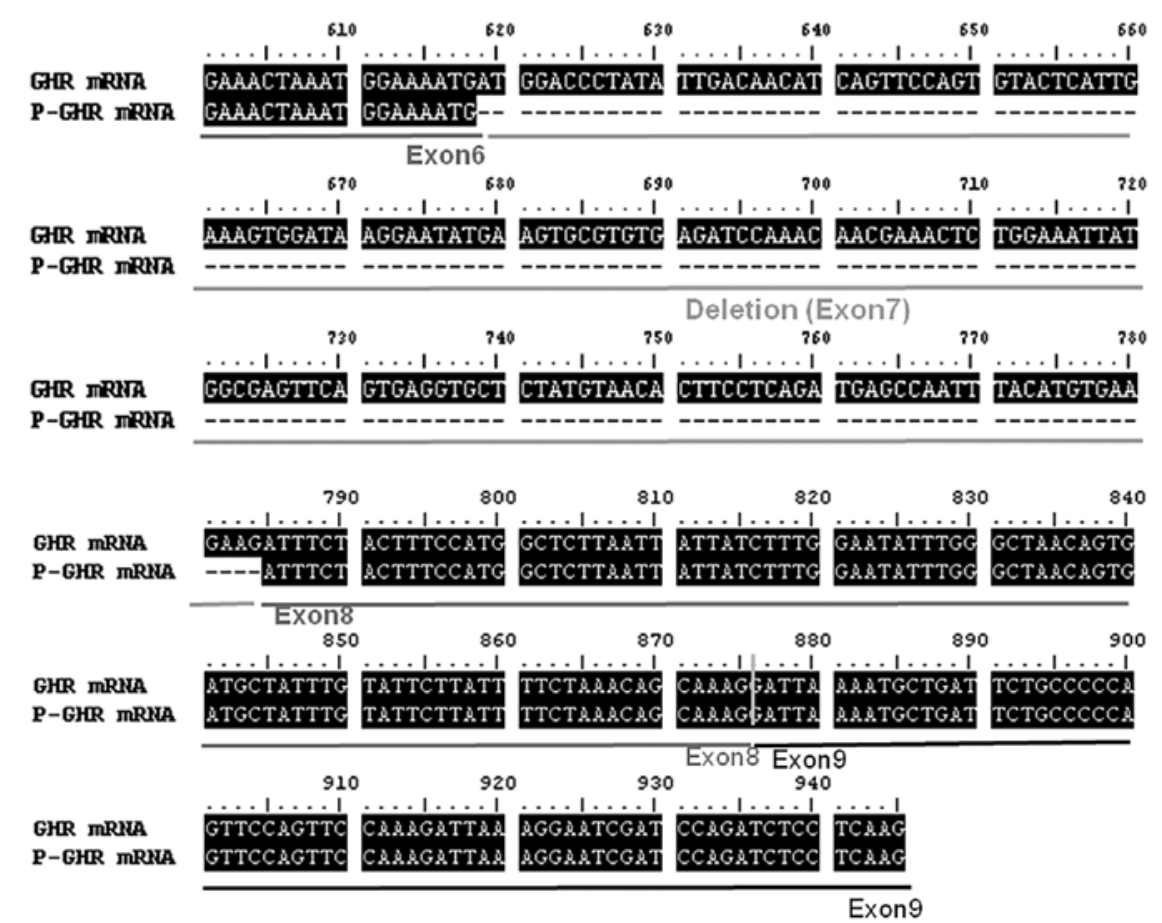

Figure 5. Sequence alignment demonstrating deletion mutation of exon 7 in the GHR mRNA in the patient. 
insulin stimulation revealed the significant difference from the general pattern of normal control (Fig. 3). The patient's serum IGF-1 and IGFBP-3 levels were low, $<25 \mathrm{ng} / \mathrm{ml}$ and $<1.2 \mathrm{mg} / 1$, respectively. On the brain MRI scanning, there was no evidence of other abnormalities including brain tumor.

Molecular studies. No germline mutation of the GHR gene including intron-exon boundaries was found in the patient and his family members. A complete deletion of exon 7 (c.619_784 del) of the GHR mRNA was observed. By analysis of agarose gel electrophoresis, a deletion of 166 base pairs in exon 7 was found (Fig. 4). It was verified via direct DNA sequencing analysis that 166 bases in exon 7 were completely deleted (Fig. 5). The deletion results in an 8-base-frameshift from the 207 th codon and a premature termination at the 214th codon of the GHR mRNA. It was considered to be a frame shifting change from methionine in codon 207, with the new reading frame ending in a stop codon, M207 fs. X8.

\section{Discussion}

We report a 2-year-old patient with NF-1 who presented postnatal growth failure with decreased growth velocity. This patient exhibited very high GH concentrations after stimulation with insulin and very low baseline levels of serum IGF-1 and IGFBP3. The patient was ultimately diagnosed as having GHIS through molecular analysis.

GHIS have been attributed to genetic defects along the GH-IGF-1 axis. GH-IGF-1 axis plays a key role for body growth. Therefore, GHIS shows the pathologic conditions associated with low serum IGF-1 and IGFBP3 concentrations, as well as, normal or elevated serum GH concentrations, leading to postnatal growth failure including various clinical facial findings (8). An analysis that investigated growth patterns in untreated patients with GHIS has revealed that most patients showed reduced growth velocity and their growth charts were similar to those with GH deficiency or IGF-1 gene deletion (9).

A GH secretory problem was highly suspected as the etiology of growth failure in our patient because the patient demonstrated postnatal growth retardation and decreased height growth velocity. In the present study, other hormonal secretory functions were normal but serum GH concentrations remained very high after stimulation with insulin. Also, the basal serum IGFBP3 and IGF-1 levels were too low to measure quantitatively. These results reveal that the patient has GHIS and the growth failure would be associated with it, not NF-1.

NF-1 related factors causing postnatal growth failure were not found in the patient. The exact mechanism of growth failure in NF-1 remains unclear, but it is known to be associated with NF-1 itself or its complications (10). These complications include central nervous system tumors, especially suprasellar lesions such as an optic glioma, true precocious puberty, GH deficiency, hypothyroidism, and abnormal skeletal development (11). In particular, GH deficiency and true precocious puberty are the major risk factors of short stature in NF-1 that are highly associated with central nervous system pathology (2). No abnormal findings were observed on MRI scanning of the neuro-musculo-skeletal system in our patient. In addition, the possibility of familial short stature as the etiology was excluded because the heights of the patient's family members were all within normal limits.

It has been reported that in NF-1 patients during puberty, growth spurt was slightly decreased and height according to age gradually reduced, and eventually adult final heights in NF-1 patients were less than those in normal individuals, whereas growth velocity remained within normal range in prepubertal stage $(9,12)$. Because our patient showed gradually reduced growth velocity since birth, the growth curve was different from that of other NF-1 patients. Considering the reduced growth velocity, low serum IGF-1 and IGFBP3 levels and abnormal serum GH secretory pattern in the $\mathrm{GH}$ stimulation test, we strongly suggested that the short stature of this patient is due to GHIS, not NF-1.

Molecular studies were performed in order to investigate whether the growth retardation in our patient is associated with molecules involved in the intracellular signaling cascade of the GH-IGF-1 axis. We found a novel mutation of $G H R$ mRNA, a complete deletion of exon 7, in the patient. Because of the deletion and resulting frameshift, the mutation results in a premature termination at the 214th codon (M207 fs. X8) of the $G H R$ gene. Exon 7 encodes a part of the extracellular domain of the GHR protein $(13,14)$. Therefore, the deletion mutation of exon 7 is considered to make a truncated receptor protein, and then the GH signal can not be transmitted into the cell. Reportedly, almost all mutations causing Laron syndrome and GHIS encode the extracellular domains of the GHR gene, while other mutations encode the cytoplasmic domain $(15,16)$.

In the reports regarding $G H R$ mutation, mRNA mutations of the GHR are uncommon, with splicing errors by mutations of the flanking region of exon being the majority (17). Rarely, mutations due to addition of a pseudoexon in an intron were reported (18-20). The patient in the present study is the first reported case having a GHIS with NF-1, who showed extensive deletion of the GHR gene mRNA. To clarify the mechanism of the disease-causing mutation, further studies are required.

\section{Acknowledgements}

We thank the family for participation in this study. This study was supported by the 2009 Eulji Research Grant (EJRG-09005-12E13).

\section{References}

1. Neurofibromatosis. Conference statement. National Institutes of Health Consensus Development Conference. Arch Neurol 45: 575-578, 1988

2. Carmi D, Shohat M, Metzker A and Dickerman Z: Growth, puberty, and endocrine functions in patients with sporadic or familial neurofibromatosis type 1: a longitudinal study. Pediatrics 103: 1257-1262, 1999.

3. Kofoed EM, Hwa V, Little B, et al: Growth hormone insensitivity associated with a STAT5b mutation. N Engl J Med 349: 1139-1147, 2003.

4. Hwa V, Little B, Adiyaman P, et al: Severe growth hormone insensitivity resulting from total absence of signal transducer and activator of transcription 5b. J Clin Endocrinol Metab 90: 4260-4266, 2005.

5. Laron Z, Pertzelan A and Mannheimer S: Genetic pituitary dwarfism with high serum concentration of growth hormone - a new inborn error of metabolism? Isr J Med Sci 2: 152-155, 1966.

6. Laron Z: Laron syndrome (primary growth resistance or insensitivity): the personal experience 1958-2003. J Clin Endocrinol Metab 89: 1031-1044, 2004. 
7. Vidal F, Farssac E, Altisent C, Puig L and Gallardo D: Rapid hemophilia A molecular diagnosis by a simple DNA sequencing procedure: identification of 14 novel mutations. Thromb Haemost 85: 580-583, 2001.

8. Gluckman PD, Gunn AJ, Wray A, et al: Congenital idiopathic growth hormone deficiency is associated with prenatal and early postnatal growth failure. J Pediatr 121: 920-923, 1992.

9. Wood KA, Cabacho-Hubner C, Savage MO and Clark AJ: Intrauterine growth retardation and postnatal growth failure associated with deletion of insulin-like growth factor I gene. N Eng J Med 335: 1363-1367, 1996.

10. Cnossen MH, Stam EN, Cooiman LC, et al: Endocrinologic disorders and optic pathway gliomas in children with neurofibromatosis type 1. Pediatrics 100: 667-670, 1997.

11. Szudeck J, Birch P and Friedman JM: Growth in North American white children with neurofibromatosis 1 (NF1). J Med Genet 37: 933-938, 2000

12. Clementi M, Milani S, Mammi I, et al: Neurofibromatosis type 1 growth charts. Am J Med Genet 87: 317-323, 1999.

13. Berg MA, Argente J, Chernausek S, et al: Diverse growth hormone receptor gene mutations in Laron syndrome. Am J Hum Genet 52: 998-1005, 1993.

14. Edens A and Talamantes F: Alternative processing of growth hormone receptor transcripts. Endocr Rev 19: 559-582, 1998
15. Rosenblooma AL and Guevara-Aguirreb J: Lessons from the genetics of Laron syndrome. Trends Endocrinol Metab 9: 276-283, 1998.

16. Clayton PE, Freeth JS and Norman MR: Congenital growth hormone insensitivity syndromes and their relevance to idiopathic short stature. Clin Endocrinol (Oxf) 50: 275-283, 1999.

17. David A, Metherell LA, Clark AJ, Camacho-Hübner C and Savage MO: Diagnostic and therapeutic advances in growth hormone insensitivity. Endocrinol Metab Clin North Am 34: 581-595, 2005

18. Metherell LA, Akker SA, Munroe PB, et al: Pseudoexon activation as a novel mechanism for disease resulting in atypical growthhormone insensitivity. Am J Hum Genet 69: 641-646, 2001.

19. Maamra M, Milward A, Esfahani HZ, et al: A 36 residues insertion in the dimerization domain of the growth hormone receptor results in defective trafficking rather than impaired signaling. J Endocrinol 188: 251-261, 2006.

20. David A, Camacho-Hübner C, Bhangoo A, et al: An intronic growth hormone receptor mutation causing activation of a pseudoexon is associated with a broad spectrum of growth hormone insensitivity phenotypes. J Clin Endocrinol Metab 92: 655-659, 2007. 